\title{
INVESTIMENTO DE IMPACTO E GRANTMAKING: VISÕES CONCEITUAIS DISTINTAS PARA O INVESTIMENTO SOCIAL PRIVADO BRASILEIRO
}

\author{
Jessica Sklair
}

\section{// resumo}

Apesar de ligeiras mudanças ocorridas ao longo dos últimos anos, o investimento social privado (ISP) brasileiro ainda apresenta baixo volume de grantmaking (repasse de recursos) às organizações da sociedade civil (OSC). Este artigo discute a possibilidade de tal cenário se dever a diferenças conceituais na visão do ISP e da sociedade civil para o desenvolvimento socioeconômico do país, cujas raízes podem remontar à história das origens do ISP e das OSC no plano nacional. O artigo apresenta também a emergência recente da prática de investimento de impacto no Brasil, sugerindo que, apesar de trazer grandes inovações técnicas para o âmbito do ISP, as ações ainda refletem divergências entre tais visões para o desenvolvimento social e, assim, fortalece a tendência histórica do ISP brasileiro de se afastar da prática do grantmaking direcionado às OSC.

palavras-chave: investimento social privado | organizações da sociedade civil | grantmaking | investimento de impacto. 


\section{OS ARTIGOS GIFE}

A série Artigos GIFE publica reflexões e análises de pesquisadores brasileiros de diferentes áreas do saber com o objetivo de estimular, ampliar e disseminar a produção de conhecimento qualificado sobre o campo da filantropia, do investimento social privado e da sociedade civil no Brasil.

A partir da premissa de que a produção de conhecimento sobre esses temas tem um papel fundamental na expansão, diversificação e qualificação da ação pública pela sociedade, a iniciativa também pretende contribuir para ampliar as conexões entre o setor, as universidades e os centros de pesquisa, promovendo e apoiando o envolvimento de novos atores com a temática e a circulação ampliada de ideias em torno dela.

Este texto integra a terceira edição dos Artigos GIFE, que propõe a publicação mensal de artigos selecionados por meio de chamada pública e convite a autores especialistas em temáticas específicas e relevantes para o setor, buscando apoiar e fomentar a produção de conhecimento sobre o investimento social no Brasil.

O Grupo de Institutos Fundações e Empresas (GIFE) é uma organização sem fins lucrativos que reúne associados de origem empresarial, familiar ou independente que investem em projetos de interesse público. Criado em 1989 como grupo de troca e colaboração e institucionalizado em 1995 por 25 organizações, tornou-se referência no campo da filantropia e do investimento social privado no Brasil.

Nesses mais de 20 anos de atuação, tem contribuído para o fortalecimento de práticas e ações a serviço do bem comum no país, trabalhando para expandir, qualificar e fortalecer o investimento social privado, diversificar e ampliar atores e recursos, criando referências e estimulando boas práticas de gestão, bem como articulando o setor com a sociedade e a agenda pública. Atualmente, o GIFE reúne mais de 150 associados que, somados, aportam mais de $\mathrm{R} \$ 3$ bilhões por ano em projetos próprios e no apoio a projetos de terceiros. 
Este artigo discute as relações entre o investimento social privado (ISP) e as organizações da sociedade civil (OSC) ${ }^{1}$ no Brasil. ${ }^{2}$ Como ponto de partida, destaca-se um dado já muito debatido no setor filantrópico: o fato de que a prática do chamado grantmaking (o repasse de recursos financeiros a OSC e terceiros) seja muito mais prevalente entre os institutos e fundações em países como os Estados Unidos e o Reino Unido do que entre seus pares brasileiros, que geralmente preferem elaborar e implementar seus próprios programas.

O presente artigo busca contribuir com esse debate, começando com uma discussão do panorama geral do grantmaking no Brasil, examinado à luz de alguns dados da paisagem britânica do ISP, em um contexto comparativo trazido por um estudo próprio (SKLAIR, 2017).

Em seguida, traça um fio conector entre o cenário atual e a história das relações entre o ISP e as OSC no Brasil. Sugere que, no contexto brasileiro, os setores filantrópico e da sociedade civil organizada caracterizam-se por distintas visões conceituais sobre o desenvolvimento social e econômico do país, inibindo o apoio do ISP, por meio do grantmaking, às OSC.

A última parte do artigo aborda a emergência, ao longo da última década, do investimento de impacto, prática que, ao contrário do grantmaking, cresce rapidamente entre os investidores sociais brasileiros. $\mathrm{O}$ artigo termina argumentando que, apesar de representar uma grande novidade técnica no âmbito do ISP, o investimento de impacto também reflete continuidades em relação a formas anteriores de ISP nacional, que tradicionalmente resistiam a uma aproximação maior com a sociedade civil.

\footnotetext{
1 Mundialmente, e mesmo no Brasil, existem ideias diferentes sobre o uso do termo OSC, e quais organizações devem ou não levar esse título. Neste artigo, essa nomenclatura é usada referindo-se a organizações de base, movimentos sociais e outras formas de ativismo da sociedade civil organizada, cujas raízes remontam ao setor progressivo das organizações não-governamentais (ONG) que surgiu durante a ditadura militar brasileira (1964-1986). Mendonça, Alves e Nogueira (2016, p. 594-597) fazem uma ampla discussão do uso do termo OSC no Brasil.

$2 \mathrm{O}$ artigo baseia-se em projetos de pesquisa próprios sobre ISP e investimento de impacto no Brasil e na Inglaterra, financiados pelo Royal Anthropological Institute (Emslie Horniman Fund Sutasoma Award, 2008), o British Academy (Small Research Grant, 2018) e Economic and Social Research Council (Postdoctoral Fellowship, 2018-2019).
} 


\section{GRANTMAKING NO BRASIL: PANORAMA GERAL E MUDANCAS RECENTES}

Grantmaking se define como o repasse de recursos financeiros a organizações, indivíduos ou movimentos sociais da sociedade civil, constituindo-se em uma das formas mais importantes pelas quais a filantropia pode apoiar a sociedade civil e fortalecer a diversidade de vozes e atividades nela presente, trabalhando em prol de uma sociedade mais democrática e representativa (ARAÚJO e JUNQUEIRA, 2018; HOPSTEIN, 2018b).

Tanto o Brasil quanto o Reino Unido são países com sociedades civis fortes e dinâmicas: segundo os últimos dados disponíveis, o Brasil conta com cerca de 237.000 OSC (IBGE, 2019) e o Reino Unido, com 166.000 (NCVO, 2019). Entre as diferenças encontradas no ISP do Brasil e do Reino Unido, porém, a porcentagem de capital filantrópico destinado ao grantmaking para as OSC se destaca fortemente. Em 2018, 35\% do ISP brasileiro foi destinado a programas, ações sociais ou gestão de terceiros por meio de grantmaking e de outras formas de investimento, incluindo o investimento de impacto (GIFE, 2019, p. 45), enquanto cerca de 70\% do ISP britânico destinava-se ao grantmaking (PHAROAH e WALKER, 2019, p. 10). ${ }^{3}$ No Brasil, portanto, grantmaking para as OSC representa prática secundária entre os institutos e fundações, que geralmente preferem usar a maior parte dos recursos na elaboração de seus próprios programas sociais.

É importante reconhecer, ao discutir esse panorama, que existem outras maneiras de apoiar as OSC, além do repasse direto de recursos na forma de grantmaking. O ISP da elite brasileira se dedica mais a essas outras atividades, que incluem a contratação de OSC para implementar programas e projetos elaborados por institutos e fundações, e a elaboração, por tais instituições, de projetos próprios nas áreas de fortalecimento institucional de OSC e de desenvolvimento local, territorial e comunitário (GIFE, 2019, p. 149). Trata-se, sem dúvida, de atividades importantes e valiosas para a sociedade civil organizada, mas em todas elas o controle e o poder de decisão sobre o uso de recursos permanece nas mãos do investidor. É somente com o repasse de recursos diretamente às OSC que elas têm autonomia de elaborar e implementar seus próprios projetos, determinando e seguindo, dessa forma, suas próprias estratégias de mudança social (ARAÚJO e JUNQUEIRA, 2018; HARTNELL e MILNER, 2018).

Ao longo dos últimos dez anos, houve aumento da proporção de recursos repassados a terceiros por institutos e fundações filantrópicas. Segundo o Censo GIFE de 2009-2010, somente $20 \%$ dos recursos investidos pelos seus associados foram doados a terceiros, enquanto $60 \%$ desse montante foi aplicado em projetos próprios e, o restante, usado para cobrir custos administrativos e outras despesas (GIFE, 2010, p. 56). O Censo GIFE de 2018 mostra uma elevação de repasses, com 35\% dos recursos agora destinados a terceiros e $50 \%$ a atividades próprias (GIFE, 2019, p. 45). ${ }^{4}$

O aumento na proporção de recursos destinada a terceiros demonstra o sucesso de uma série de iniciativas, desenhadas ao longo da última década, para fortalecer as práticas de grantmaking e doação no Brasil. Entre elas, destacam-se projetos do GIFE, apoiados ou em parceria com vários institutos e

\footnotetext{
3 Dados baseados em pesquisas feitas entre os 133 respondentes do Censo GIFE 2018 no Brasil, e entre as 300 maiores fundações britânicas (2017-18), escolhidos por nível de recursos destinados ao ISP.

4 Vale mencionar que o Censo GIFE inclui tanto OSC quanto "negócios de impacto ou acelerados e organizações intermediárias" entre os diversos tipos de organização destacados nos seus dados sobre repasse de recursos para terceiros (GIFE, 2019, p. 51). No entanto, incluir esses dois tipos de repasse de recursos - investimento de impacto e grantmaking para OSC - na mesma categoria é problemático. Primeiro porque, como discutido a seguir, essas duas práticas são conceitualmente muito diferentes. E, segundo, porque isso dificulta a avaliação do real aumento na prática de grantmaking para OSC entre os investidores sociais, pois o Censo não demonstra a porcentagem do total de recursos repassados para terceiros destinada a cada tipo de organização.
} 
fundações, incluindo o Fundo BIS, a Rede Temática de Grantmaking e o Projeto Sustentabilidade Econômica das Organizações da Sociedade Civil (em parceria com a FGV Direito SP), além das iniciativas Descubra sua Causa (projeto do Instituto para o Desenvolvimento do Investimento Social, IDIS) e Dia de Doar (da Associação Brasileira de Captadores de Recursos, ABCR). ${ }^{5}$

Considerando, porém, o trabalho desenvolvido por essas organizações, o aumento na proporção de recursos filantrópicos destinados ao grantmaking visto ao longo dos últimos anos é relativamente pequeno. Algumas razões já foram sugeridas, incluindo a falta de conhecimento entre os investidores sobre o trabalho e objetivos da sociedade civil e uma tendência histórica de pouca confiança nos modos de operação das OSC (HARTNELL e MILNER, 2018; MENDONÇA, ALVES e NOGUEIRA, 2016). Em paralelo, poucos incentivos jurídicos e fiscais para estimular o repasse de recursos para terceiros e o imposto sobre transmissão causa mortis e doação (ITCMD) no Brasil também são citados como explicação (HARTNELL e MILNER, 2018).

Também relevante nesse debate foi a expectativa, comum antigamente entre profissionais do ISP, de que um aumento no número de fundações e institutos familiares no âmbito do ISP brasileiro - que tradicionalmente era dominado por institutos empresariais (NOGUEIRA, 2013) - poderia levar a um compromisso maior com o grantmaking. Contava-se com a maior liberdade de atuação dos institutos familiares, que não enfrentam os riscos de reputação da empresa que preocupam institutos empresariais no apoio a certas causas, como aquelas consideradas mais politicamente sensíveis (LESSA e ROSSETTI, 2005; DEGENSZAJN, 2013). Porém, mesmo com o aumento recente no número de fundações familiares no Brasil, a expectativa não se concretizou. Com algumas exceções importantes, as fundações familiares recém-fundadas também preferem operar seus próprios programas, em vez de repassar recursos para terceiros (HARTNELL e MILNER, 2018; ROSSETTI, 2018).

Além de todos esses fatores, este artigo sugere que existe outra questão pouco contemplada no debate em torno da baixa incidência de grantmaking entre os investidores sociais brasileiros. Trata-se da visão conceitual do ISP para o desenvolvimento socioeconômico do país - ou seja, a maneira como o ISP brasileiro entende causas e soluções para os problemas sociais - e o desencontro entre tal visão e a visão paralela das OSC. Para melhor entender esse argumento, importa examinar a história das relações entre o ISP e as OSC, começando com a época da emergência da sociedade civil organizada no Brasil.

\section{INVESTIMENTO SOCIAL PRIVADO E A SOCIEDADE CIVIL ORGANIZADA: UM OLHAR HISTÓRICO}

No Brasil, a emergência da sociedade civil organizada foi estimulada pelo golpe militar de 1964, quando a insatisfação crescente com a opressão de direitos políticos e humanos refletiu-se em uma onda de pequenos movimentos populares. Fora do radar do governo militar, esses movimentos assumiram a forma de grupos comunitários informais e auto-organizados para atender suas próprias necessidades, na ausência da provisão do Estado. Tais movimentos enfrentaram uma série de problemas sociais e, enquanto trabalhadores rurais organizavam ocupações de terra, associações de moradores nas periferias e favelas das cidades realizavam mutirões para a construção de suas casas, abriam creches comunitárias e organizavam o acesso ao fornecimento de água e luz (FERNANDES, 1994). Tais movimentos receberam grande apoio da Igreja Católica, especialmente dos discípulos progressistas da Teologia da Libertação (FERNANDES, 1994; LANDIM, 1988). Apesar de só se adotar o termo

5 Algumas dessas iniciativas direcionam-se a um público amplo de possíveis doadores, que vai além de institutos e fundações, o que não thes tira a relevância na paisagem do ISP brasileiro. 
organização não-governamental (ONG) um pouco mais tarde, começaram a surgir, nesse contexto, a primeira onda de ONG no país ${ }^{6}$, em meados dos anos 1970. Essas pequenas organizações informais foram criadas por intelectuais da classe média, muitos deles envolvidos em atividades de resistência, para apoiar os movimentos populares com assessoria técnica e financeira (LANDIM, 1998).

Porém, essas ONG emergentes se caracterizavam por ter objetivos e métodos radicalmente diferentes das instituições de filantropia das elites da época. A filantropia até então se realizava de diferentes formas, mas com destaque ao apoio tradicional de instituições religiosas de caridade - como a rede brasileira de hospitais da Santa Casa (LANDIM, 1993) - e à criação de projetos sociais por imigrantes comercialmente bem-sucedidos, direcionados a membros de suas próprias comunidades, como os hospitais Sírio-Libanês e Albert Einstein (SKLAIR, 2010). Em paralelo, formavam-se nos anos 1950 e nas décadas seguintes os primeiros institutos e fundações empresariais, gerenciados por profissionais da área de recursos humanos e criados para prover benefícios aos funcionários.

Ademais, enquanto o Estado militar cultivou relações próximas às elites corporativas responsáveis por esses projetos, a identidade do emergente setor das ONG brasileiras formou-se explicitamente em oposição ao regime militar (FERNANDES, 1994). A filantropia brasileira não foi, portanto, uma fonte significativa de financiamento para as primeiras ONG deste país. Na ausência de apoio local, tais organizações dependeram do financiamento e apoio institucional de ONG e fundações filantrópicas do exterior, e da ajuda oficial bilateral, por meio da assim chamada cooperação internacional (MENDONÇA, ALVES e NOGUEIRA, 2013).

As ONG tiveram uma presença importante nos eventos que levaram ao fim da ditadura militar em 1984, e o setor rapidamente assumiu um papel central na construção da nova democracia brasileira, incluindo a elaboração da Constituição Brasileira de 1988 (HADDAD e OLIVEIRA, 2001). Novas políticas públicas neoliberais, que visavam a terceirização de prestação de serviços públicos, também levaram à contratação e ao financiamento de muitas ONG pelo Estado nessa época (MENDONÇA, ALVES e NOGUEIRA, 2013). Até o início da década de 1990, portanto, o setor de ONG já havia ganhado grande visibilidade e influência no Brasil, uma mudança radical considerando sua militância semiclandestina na década anterior.

Ao mesmo tempo, a nova paisagem política brasileira também criou condições para novas formas de filantropia entre as elites. $\mathrm{O}$ advento da política econômica neoliberal levou a uma desregulamentação significativa da atividade empresarial e, liberado do controle estatal, o setor corporativo brasileiro se dedicou ao fortalecimento da economia capitalista. Um compromisso maior com as questões sociais era considerado elemento importante desse projeto, e os anos 1990 foram pano de fundo para dois movimentos novos (e interligados) nessa direção: o da responsabilidade social corporativa (RSC) e o do ISP (AGÜERO, 2005; HARTNELL e MILNER, 2018; SANBORN, 2005). Nessa época, sugiram as primeiras organizações intermediárias para incentivar e organizar esses movimentos, como o próprio GIFE, o IDIS e o Instituto Ethos de Empresas e Responsabilidade Social (ETHOS).

No entanto, o novo enfoque social da elite brasileira não estimulou a prática do grantmaking para as ONG e os movimentos sociais. Embora algumas ONG recebessem financiamento estatal, como mencionado, a maioria continuava a depender financeiramente da cooperação internacional. Tal dependência em breve se converteria em um problema, pois o melhor desempenho econômico nacional nas décadas

6 Ao longo dos últimos anos, a nomenclatura "organização não-governamental” cedeu espaço para o termo mais abrangente, “organização da sociedade civil”. Nesta parte do presente artigo, porém, é usado o primeiro termo para melhor representar o período histórico em discussão. 
de 1990 e 2000, junto com a estabilidade democrática, fizeram o Brasil perder seu status de prioridade entre os financiadores estrangeiros, muitos dos quais retiraram o seu apoio (ARAÚJO, 2013; MENDONÇA, ALVES e NOGUEIRA, 2016).

Dessa época até hoje, o cenário de sustentabilidade financeira das OSC brasileiras caracteriza-se por duas tendências desafiadoras. A primeira, uma redução ainda maior nos recursos internacionais destinados ao país e, a segunda, uma grande flutuação no nível de financiamento público para as OSC, em que destaca-se especialmente o período entre 2014 e 2016, quando o valor empenhado no orçamento da União caiu drasticamente de 12,1 para 2,3 bilhões de reais (LOPEZ, 2018, p. 122). Cabe perguntar por que, face essa crise financeira crescente entre as OSC, o ISP nunca se mobilizou no sentido de ampliar significativamente seu apoio financeiro para a sociedade civil organizada?

Parece que essa história revela que os institutos e fundações do ISP e as OSC se formaram em torno de visões e objetivos muito diferentes para o desenvolvimento social do país, e esse é um dado importante no debate a respeito do baixo nível de grantmaking no Brasil. Nos anos 1990, o ISP brasileiro foi visto como uma atividade corporativa, bem como uma forma de demonstrar a capacidade das instituições do capitalismo nacional de promover o desenvolvimento social. Com esse objetivo, o ISP brasileiro já nasceu com um enfoque na educação e preparo da população para sua melhor integração no mercado de trabalho. Até hoje, esse foco ainda se reflete nas maiores áreas de atuação do ISP, representadas pelo último Censo GIFE como "educação", em primeiro lugar, e "trabalho, empreendedorismo e geração de renda”, no segundo (GIFE, 2019, p. 149).

Ao lado de um investimento maciço na área de educação, o ISP segue na elaboração de estratégias próprias para integrar melhor a população mais pobre aos mercados nacionais de trabalho formal, por exemplo, por meio de projetos de geração de renda, formação técnica e estímulo ao empreendedorismo entre os jovens. Desse jeito, a visão do ISP privilegia o mercado neoliberal existente como âmbito de soluções para os problemas sociais, tanto institucionalmente (identificando o instituto ou fundação empresarial como local ideal e legítimo de elaboração de projetos sociais) quanto conceitualmente (identificando a falta de formação e preparo para integração ao mercado de trabalho formal como a maior barreira para o combate à pobreza).

A visão do ISP para o desenvolvimento brasileiro, portanto, é muito diferente da visão das OSC e dos movimentos sociais. Do ponto de vista institucional, a história da sociedade civil organizada foi uma batalha acirrada para o reconhecimento da legitimidade de suas organizações e movimentos de base, no sentido de determinar e implementar suas próprias estratégias para a mudança social. E, no plano conceitual, a abordagem das OSC se baseia na luta pelos direitos humanos, justiça social e diminuição das desigualdades econômicas, raciais e de gênero. Esses são assuntos de poder e desigualdade sistêmicas, enraizadas na sociedade e na economia brasileira. Questões, portanto, pouco contempladas no âmbito do ISP.

Ao longo dos últimos anos, surgiu no Brasil um novo movimento em torno do conceito de "filantropia de justiça social”, que busca estimular a doação e o investimento social para atores da sociedade civil organizada trabalhando em prol dos direitos humanos e da justiça social (HOPSTEIN, 2018a). Autores escrevendo sobre esse movimento reconhecem que, no contexto brasileiro, uma nova direção do ISP para um maior compromisso com o grantmaking precisaria mais do que uma mudança na forma de operação dos institutos e fundações. Necessitaria, de fato, de uma reelaboração da visão do ISP, no sentido de contemplar as maneiras em que questões de poder e desigualdade servem para travar o desenvolvimento social do país (HOPSTEIN, 2018a; ROSSETTI, 2018). 


\section{MUDANÇAS E CONTINUIDADES: A EMERGÊNCIA DO INVESTIMENTO DE IMPACTO NA PAISAGEM DO ISP E SUA RELEVÂNCIA PARA O GRANTMAKING}

Além de os dados demonstrarem ligeiro aumento na porcentagem de recursos dedicados ao grantmaking pelos investidores sociais ao longo da última década, houve outra mudança importante na paisagem do ISP brasileiro: a emergência do investimento de impacto. O Censo GIFE de 2009-2010 sequer faz referência a essa prática, enquanto o Censo de 2018 mostra que $26 \%$ dos respondentes agora repassam recursos a negócios de impacto ou organizações intermediárias desse setor (GIFE, 2019, p. 51).

Investimento de impacto é a prática em que investidores - incluindo instituições e fundações filantrópicas, family offices e agências de desenvolvimento internacional - investem capital em negócios de impacto, definidos como "empreendimentos que têm a missão explícita de gerar impacto social e/ ou ambiental ao mesmo tempo em que produzem resultado financeiro positivo de forma sustentável" (FTFS, 2016). Trata-se de uma tendência global em rápido crescimento, que já atraiu recursos financeiros significativos ao redor do mundo. O Global Impact Investing Network (GIIN, 2019) estima o valor atual do mercado global de investimento de impacto em mais de 502 bilhões de dólares.

Ao longo da última década, o Brasil se tornou um polo regional para experimentos nesse setor. $\mathrm{O}$ mercado nacional é pequeno, mas está em crescimento; em 2016-17, uma pesquisa conduzida no Brasil identificou 69 operações, somando um total de 131 milhões de dólares, e 343 milhões de dólares de ativos alocados na gestão de investimentos de impacto (ANDE, 2018, p. 10). Esse mercado se constitui de uma diversidade de investidores, privados e institucionais, brasileiros e estrangeiros, com investimentos em uma série de negócios sociais brasileiros, especialmente nas áreas de tecnologia da informação e comunicação, educação, saúde, inclusão financeira, habitação, energia renovável e conservação da biodiversidade (ANDE, 2018). Os últimos anos foram pano de fundo para a emergência de novos instrumentos e investidores financeiros, iniciativas jurídicas para fortalecer o ambiente legal nesse âmbito e diversos eventos e publicações destinados aos investidores e aos empreendedores sociais (AINI, 2018).

Como dito, as fundações e institutos de ISP estão assumindo um papel crescente no desenvolvimento desse setor. Pesquisas mostram as potencialidades e os possíveis dilemas da maior aproximação do ISP à prática do investimento de impacto (DEBONI, 2018; HARTNELL e MILNER, 2018; MATHIAS e SANTOS, 2019). Em uma excelente análise nesse sentido, Brettas (2018) destaca várias maneiras em que o ISP pode ajudar no desenvolvimento do campo de investimento de impacto, além de apontar para o potencial dos negócios de impacto de oferecer soluções escaláveis e financeiramente sustentáveis para os problemas sociais enfrentados pelo ISP. Ao mesmo tempo, porém, o estudo recomenda que o investimento de impacto deve ser entendido como uma forma de complementar, e não de superar, outras formas de ISP, já que a lógica de mercado não é necessariamente a forma ideal - nem a mais eficaz ou eficiente - de resolver todos os tipos de problema social. E, de grande relevância para a presente discussão, adverte:

Deve haver um cuidado importante na relação entre negócios de impacto e OSC, para que os primeiros não sejam entendidos como uma “evolução” destas - OSC [são consideradas] atores fundamentais para a democracia e o desenvolvimento de certos papéis, como advocacy, controle social ou defesa de direitos (BRETTAS, 2018, p. 67).

Implícito nesse argumento é a afirmação de que, no Brasil, OSC e negócio de impacto, apesar de compartilharem o mesmo objetivo de estimular a mudança social, são organizações muito diferentes. E, para voltar ao argumento do presente artigo, investimento em negócio de impacto e repasse de recurso para OSC também são formas muito diferentes de ISP. Ademais, é possível traçar um fio condutor entre 
o entusiasmo entre investidores sociais para a nova prática de investimento de impacto e a continuidade do baixo apoio financeiro do ISP às OSC por meio de grantmaking.

A história das relações entre o ISP da elite corporativa e as OSC, detalhada anteriormente, permite colocar a recente prática do investimento de impacto no Brasil no seu contexto histórico. Ao entender o ISP brasileiro como um movimento corporativo que - como argumentado - se baseia em uma visão de mercado para fornecer soluções para os problemas sociais, pode-se ver que a prática de investimento de impacto serve para dar continuidade a tendências históricas fundamentais do ISP.

O investimento em negócios sociais certamente traz grandes inovações no plano técnico, introduzindo novos modelos de operação e instrumentos financeiros para o ISP, e sem dúvida oferece soluções inovadoras e criativas para alguns dos variados problemas sociais que o país enfrenta. No plano conceitual, porém, essa prática aprofunda e fortalece a visão tradicional do ISP para o desenvolvimento social nacional. Se o ISP previamente focava na melhor integração da população mais pobre com o mercado existente, agora - pelo

No contexto brasileiro, uma nova direção do ISP para um maior compromisso com o grantmaking precisaria mais do que uma mudança na forma de operação dos institutos e fundações. Necessitaria, de fato, de uma reelaboração da visão do ISP, no sentido de contemplar as maneiras em que questões de poder e desigualdade servem para travar o desenvolvimento social do país investimento de impacto - ele procura aplicar diretamente modelos de mercado na resolução de problemas sociais. Essa abordagem dá continuidade à ideia de que o sistema econômico existente pode ser adaptado e aperfeiçoado para conduzir ao desenvolvimento social.

Como antes, portanto, a visão do ISP praticada por investimento de impacto permanece ainda distante da abordagem das OSC e dos movimentos sociais. Os últimos continuam prestigiando uma visão para a mudança social muito diferente, baseada no combate da reprodução sistêmica da injustiça e da desigualdade na economia e na sociedade brasileira. Em paralelo, e também como antes, o ISP realizado na forma de investimento de impacto continua não elegendo as OSC como os melhores locais institucionais para provocar a mudança social: o local eleito para essa tarefa, agora, migra do instituto ou fundação empresarial para o negócio de impacto. Ambos se localizam no âmbito do mercado, diferente da OSC, que se encontra no âmbito da sociedade civil organizada.

Examinada por essa perspectiva, a emergência de investimento de impacto no âmbito do ISP mostra fortes continuidades com tendências antigas na paisagem brasileira da filantropia. Como contribuição para o debate em torno do baixo nível de grantmaking para as OSC dos investidores sociais, este texto indica, portanto, que o investimento de impacto introduz uma forma contemporânea da mesma visão conceitual de mudança social que sempre norteou o ISP. Para uma mudança no sentido de dedicar uma porcentagem muito maior de recursos filantrópicos ao grantmaking, seria necessária uma mudança expressiva nessa visão predominante. 


\section{CONCLUSÃO}

Este artigo não procurou avaliar o potencial do investimento de impacto, nem das práticas mais tradicionais do ISP brasileiro, de promover melhorias no âmbito do desenvolvimento social do país. Esses são assuntos complexos, que vão além da discussão apresentada. $\mathrm{O}$ objetivo do presente artigo foi, mais propriamente, chamar a atenção para semelhanças entre o investimento de impacto e tendências mais antigas na paisagem filantrópica brasileira, particularmente em termos do que pode revelar sobre a baixa incidência de grantmaking direcionado às OSC. Nesse sentido, há o argumento de que as diferenças conceituais entre a filantropia e as ONG, já observadas durante a época da ditadura militar, continuam a influenciar as relações contemporâneas entre o ISP e as OSC.

O tema deste artigo assume relevância especial no momento atual do país. As radicais mudanças políticas vistas ao longo dos últimos anos tiveram consequências devastadoras para muitas OSC e movimentos sociais. Além do reflexo na diminuição do financiamento público para as OSC e na perda de muitos direitos legais previamente alcançados por variados grupos sociais, a recente onda conservadora também se desdobra na criminalização das organizações e atores da sociedade civil e em um aumento assustador na incidência de ataques contra defensores dos direitos humanos (ARAÚJO e JUNQUEIRA, 2018; HARTNELL e MILNER, 2018).

Ademais, enquanto este artigo é escrito, a situação encontra-se ainda mais agravada pela crise da Covid-19. Se a crise traz, por um lado, urgentes desafios no âmbito da saúde pública, também deixa mais expostas do que nunca as desigualdades que caracterizam a sociedade brasileira, já que as populações mais vulneráveis são afetadas de maneira muito mais aguda por suas consequências sociais e econômicas. Nesse cenário, as OSC que trabalham diretamente com essas populações são tanto mais necessárias quanto mais sobrecarregadas do que nunca.

A Covid-19 estimulou uma onda de generosidade impressionante no Brasil, com mais de 4,8 bilhões de reais já doados para projetos, fundos e iniciativas relacionados à crise (ABCR, 2020), sendo grande parte vinda do setor do ISP (AOQUI, AÑÓN e PRATA, 2020). Não se sabe ainda qual porcentagem desse volume foi doada em forma de grantmaking direto para OSC. Porém, como sugerido em artigo recente por Krämer, Hopstein e Mahomed (2020), a situação atual representa uma oportunidade rara para o ISP trabalhar em parceria com as OSC, no sentido de estimular mudanças sociais sistêmicas e duradouras.

Se há uma certeza é que, no contexto atual, as OSC necessitam urgentemente de apoio, tanto financeiro quanto de reconhecimento do trabalho essencial que desenvolvem em prol de uma sociedade mais justa, igualitária e democrática. Talvez seja realmente um momento oportuno para o ISP brasileiro reavaliar sua relação histórica com a sociedade civil organizada, e definir melhor o tipo de relação que quer cultivar com ela no futuro. 


\section{REFERÊNCIAS}

ABCR - Associação Brasileira de Captadores de Recursos. Monitor das doações. Disponível em: https://www.monitordasdoacoes.org.br/. Acesso em: 12/05/2020.

AGÜERO, Felipe. The promotion of corporate social responsibility in Latin America. In: SANBORN, Cynthia; PORTOCARRERO, Felipe. (eds.). Philanthropy and social change in Latin America. Cambridge, Massachusetts: Harvard University Press, 2005, p. 103-134.

AINI - ALIANÇA PELOS INVESTIMENTOS E NEGÓCIOS DE IMPACTO. Conquistas e avanços do ecossistema de investimentos e negócios de impacto no Brasil: Relatório 2018. 2018. Disponível em: https://aliancapeloimpacto.org.br/ publicacao/relatorio-2018-conquistas-e-avancos-do-ecossistema-de-investimentos-e-negocios-de-impacto-no-brasil/. Acesso em: $22 / 01 / 2020$

ANDE - Aspen Network of Development Entrepreneurs. The impact investing landscape in Brazil: trends 2016 \& 2017. 2018. Disponível em: https://cdn.ymaws.com/www.andeglobal.org/resource/resmgr/brazil_files/ImpInvBrazil_Eng_2018. pdf. Acesso em: 22/01/2020.

AOQUI, Cássio; AÑÓN, Rachel; PRATA, Vanessa. Os primeiros 60 dias de Covid-19 no Brasil: tendências em filantropia, investimento social e o campo de impacto social durante a pandemia. Folha de S. Paulo. 28 de abril de 2020. Disponível em: https://www1.folha.uol.com.br/empreendedorsocial/2020/04/os-primeiros-60-dias-de-covid-19-no-brasil.shtml?utm_campaign=emergencia_covid-19_news05_-_29042020\&utm_medium=email\&utm_source=RD+Station. Acesso em: 29/04/20.

ARAÚJO, Ana Valéria. Human rights funding in Brazil. Open Democracy. 12 nov. 2013. Disponível em: https://www.opendemocracy.net/en/openglobalrights-openpage/human-rights-funding-in-brazil/. Acesso em: 22/01/2020.

ARAÚJO, Ana Valéria; JUNQUEIRA, Maíra. Filantropia de justiça social e defesa dos direitos humanos. In: HOPSTEIN, Graciela (org.). Filantropia de justiça social, sociedade civil e movimentos sociais no Brasil. Rio de Janeiro: E-papers, 2018, p. 85-93.

BRETTAS, Gabriela. 2018. Olhares sobre a atuação do investimento social privado no campo de negócios de impacto. Temas do Investimento Social. GIFE, 2018. Disponível em: https://sinapse.gife.org.br/download/olhares-sobre-a-atuacao-do-investimento-social-privado-no-campo-de-negocios-de-impacto. Acesso em: 12/05/2020.

DEBONI, Fábio. Investimento social privado como expressão da filantropia: dilemas e caminhos. In: HOPSTEIN, Graciela (org.). Filantropia de justiça social, sociedade civil e movimentos sociais no Brasil. Rio de Janeiro: E-papers, 2018, p. 227-235.

DEGENSZAJN, André. Características e desafios do investimento social no Brasil: uma conversa com André Degenszajn. In: MENDONÇA, Patrícia M. E.; ALVES, Mário Aquino; NOGUEIRA, Fernando A. (orgs.) Arquitetura institucional de apoio às organizações da sociedade civil no Brasil. São Paulo: FGV, 2013, p. 233-239.

FERNANDES, Rubem Cesar. Privado porém público: o terceiro setor na América Latina. Rio de Janeiro: RelumeDumará, 1994

FTFS - FORÇA TAREFA DE FINANÇAS SOCIAIS. Fundações e institutos corporativos investindo em negócios de impacto. 2016. Disponível em: https://aliancapeloimpacto.org.br/wp-content/uploads/2020/02/guia-investimento-de-fundacoes-e-institutos-corporativos-em-negocios-de-impacto.pdf. Acesso em: 22/01/2020.

GIFE - Grupo de Institutos, Fundações e Empresas. Censo GIFE 2009-2010. 2010. Disponível em: https://sinapse.gife.org. br/download/censo-gife-2009-2010. Acesso em: 22/01/2020.

GIFE - Grupo de Institutos, Fundações e Empresas. Censo GIFE 2018. 2019. Disponível em: https://sinapse.gife.org.br/ download/censo-gife-2018. Acesso em: 22/01/2020.

GIIN - Global Impact Investing Network. Sizing the impact investment market. 2019. Disponível em: https://thegiin.org/ research/publication/impinv-market-size. Acesso em: 22/01/2020. 
HADDAD, Sérgio; OLIVEIRA, Anna Cynthia. As organizações da sociedade civil e as ONGs de educação. Cadernos de Pesquisa, n. 112, p. 61-83, 2001. DOI: http://dx.doi.org/10.1590/S0100-15742001000100003.

HARTNELL, Caroline; MILNER, Andrew. Philanthropy in Brazil: a working paper. Philanthropy for social justice and peace. 2018. Disponível em: http://www.psjp.org/wp-content/uploads/2018/05/PHILANTHROPY-IN-BRAZIL-MAY-2018. pdf. Acesso em: 22/01/2020.

HOPSTEIN, Graciela. Uma aproximação ao campo da filantropia de justiça social. In: HOPSTEIN, Graciela (org.). Filantropia de justiça social, sociedade civil e movimentos sociais no Brasil. Rio de Janeiro: E-papers, 2018a, p. 11-29.

HOPSTEIN, Graciela. Transformando a filantropia no Brasil: o fenômeno da rede de filantropia para a justiça social. In: HOPSTEIN, Graciela (org.). Filantropia de justiça social, sociedade civil e movimentos sociais no Brasil. Rio de Janeiro: E-papers, 2018b, p. 71-83.

IBGE - Instituto Brasileiro de Geografia e Estatística. As fundações privadas e associações sem fins lucrativos no Brasil: 2016. 2019. Disponível em: https://www.ibge.gov.br/estatisticas/economicas/outras-estatisticas-economicas/9023-as-fundacoes-privadas-e-associacoes-sem-fins-lucrativos-no-brasil.html?edicao=24159\&t=publicacoes. Acesso em: 22/01/2020.

KRÄMER, Romy; HOPSTEIN, Graciela; MAHOMED, Halima. Social movements in times of pandemic: the moment for philanthropy has arrived. Alliance Blog. 26 de março 2020. Disponível em: https://www.alliancemagazine.org/blog/social-movements-in-times-of-pandemic-the-moment-for-philanthropy-has-arrived/. Acesso em: 22/04/2020.

LANDIM, Leila. Experiência militante: histórias das assim chamadas ONGs. In: LANDIM, Leila (org.). Ações em sociedade: militância, caridade, assistência etc. Rio de Janeiro: NAU, 1998.

LANDIM, Leila. Defining the nonprofit sector: Brazil. Working papers of the Johns Hopkins comparative nonprofit sector project, n. 9. The Johns Hopkins Institute for Policy Studies, 1993.

LANDIM, Leila. A serviço do movimento popular: as organizações não-governamentais no Brasil. In: LANDIM, Leila (org.). Sem fins lucrativos: as organizações não-governamentais no Brasil. Rio de Janeiro: Instituto de Estudos da Religião (ISER), 1988.

LESSA, Cindy; ROSSETTI, Fernando. Brazil: creating a more diverse sector. Alliance Magazine. 1 de dezembro de 2005. Disponível em: www.alliancemagazine.org/feature/brazil-creating-a-more-diverse-sector/. Acesso em: 22/01/2020.

LOPEZ, Felix Garcia. Perfil das organizações da sociedade civil no Brasil. Brasília: Ipea, 2018.

MATHIAS, Ana Luiza Terra Costa; SANTOS, Paula Santana. Investimento social privado e negócios de impacto: possibilidades de apoio ao setor de impacto no Brasil. Artigos GIFE, v. 1, n. 1, artigo 4, 2019.

MENDONÇA, Patrícia; ALVES, Mário Aquino; NOGUEIRA, Fernando. Civil society organisations and the fight for rights in Brazil: analysis of an evolving context and future challenges. Development in Practice, v. 26, n. 5, p. 592-605, 2016. DOI: 10.1080/09614524.2016.1190318.

MENDONÇA, Patrícia; ALVES, Mário Aquino; NOGUEIRA, Fernando. Quadro geral da arquitetura de apoio às OSCs: tendências e reflexões. In: MENDONÇA, Patrícia M. E.; ALVES, Mário Aquino; NOGUEIRA, Fernando A. (orgs.). Arquitetura institucional de apoio às organizações da sociedade civil no Brasil. São Paulo: FGV, 2013, p. 25-41.

NCVO - National Council for Voluntary Organisations. The UK civil society almanac 2019. 2019. Disponível em: https:// data.ncvo.org.uk/. Acesso em: 22/01/2020.

NOGUEIRA, Fernando A. O investimento social corporativo e sua atuação em direitos humanos no Brasil: uma trajetória desafiadora. In: MENDONÇA, Patrícia M. E.; ALVES, Mário Aquino; NOGUEIRA, Fernando A. (orgs.) Arquitetura institucional de apoio às organizações da sociedade civil no Brasil. São Paulo: FGV, 2013, p. 207-221.

PHAROAH, Cathy; WALKER, Catherine. Foundation giving trends 2019. Association of Charitable Foundations. 2019. Disponível em: https://www.acf.org.uk/policy-practice/research-publications/foundation-giving-trends-2019. Acesso em: 22/01/2020. 
ROSSETTI, Fernando. Brazil, philanthropy and inequality. Alliance Blog. 11 de julho de 2018. Disponível em: https://www. alliancemagazine.org/blog/philanthropy-for-social-justice-peace-brazil-philanthropy-and-inequality/. Acesso em: 22/01/2020.

SANBORN, Cynthia. Philanthropy in Latin America: historical traditions and current trends. In: SANBORN, Cynthia; PORTOCARRERO, Felipe (orgs.). Philanthropy and social change in Latin America. Cambridge, Massachusetts: Harvard University Press, 2005, p. 3-29.

SKLAIR, Jessica. A filantropia paulistana: ações sociais em uma cidade segregada. São Paulo: Humanitas, 2010.

SKLAIR, Jessica. Philanthropy in Brazil and the UK: wealth, responsibility and the pursuit of social change by economic elites. Tese de doutorado. Goldsmiths, University of London, 2017. DOI: https://doi.org/10.25602/GOLD.00020738. 


\section{A AUTORA}

\section{Jessica Sklair \\ js222@cam.ac.uk}

Antropóloga inglesa, com mestrado pela Faculdade de Filosofia, Letras e Ciências Humanas (FFLCH) da Universidade de São Paulo (USP) e doutorado pelo Departamento de Antropologia da Goldsmiths, Universidade de Londres. Atualmente é pesquisadora no Margaret Anstee Centre for Global Studies da Universidade de Cambridge, onde pesquisa novas formas de relacionamento do setor privado nos âmbitos da filantropia e do desenvolvimento internacional no Brasil e na Inglaterra. É também associada do Institute of Latin American Studies, School of Advanced Study, Universidade de Londres. 


\section{artigos GIFE}

Supervisão: José Marcelo Zacchi e Gustavo Bernardino

Coordenação: Carolina Magosso

Produção editorial: Gleice Regina Guerra

Apoio: Graziela Santiago

Diagramação: Alastra, Comunical

Impressão: Forma Certa

ISSN: 2674-8061

DOI: doi.org/10.33816/gife.20200201a2

(C) 2020 GIFE - Grupo de Institutos Fundações e Empresas

\section{(c) (P) 8}

BY NC

Este material é disponibilizado sob a licenca Creative Commons Atribuição Não Comercial 4.0 Internacional. http://creativecommons.org/licenses/by-nc/4.0

As opiniões e análises expressas nesta publicação não necessariamente refletem as do GIFE.

Apoio institucional

Alana

Ford Foundation

Fundação Bradesco

Fundação Lemann

Fundação Tide Setubal

Instituto Unibanco

Laudes Foundation

\section{OGIFE}

